\title{
Well-Being Before and After Pregnancy Termination: The Consequences of Abortion and Miscarriage on Satisfaction With Various Domains of Life
}

\section{Björn Huss $^{1}$ (D)}

Accepted: 17 December 2020 / Published online: 4 January 2021

(C) The Author(s) 2021

\begin{abstract}
The consequences of pregnancy outcomes other than live birth on subjective well-being have rarely been analysed in research to date. This study examines pre-event determinants as well as the temporary and long-term effects of induced abortion and miscarriage (spontaneous abortion) on satisfaction with various domains of life. The data were derived from the German Panel Analysis of Intimate Relationships and Family Dynamics (pairfam). The longitudinal sample consists of 5331 women of reproductive age, of whom 214 women had an induced abortion, 331 women had a miscarriage, and 1156 women had a live birth during the observation period. First, pre-event measures of women who had an induced abortion and women who had a miscarriage were compared with the pre-event measures of those women who gave birth. Second, fixed effects models were used to examine whether overall or domain-specific life satisfaction changed following a pregnancy termination. The results show that pregnancies resulting in abortion or miscarriage were less frequently preceded by pregnancy intentions compared to those resulting in live birth, and that induced abortion - but not miscarriage — was furthermore accompanied by lower pre-event satisfaction than live birth. Following both miscarriage and induced abortion, women experienced temporary declines in overall life satisfaction and showed persistently lower satisfaction in several domains of life. With regard to induced abortion, pre-event measures were a better predictor of overall well-being than the consequences of the event itself. Low life satisfaction might therefore be a risk factor for having an abortion rather than a result.
\end{abstract}

Keywords Abortion · Miscarriage $\cdot$ Life satisfaction · Fixed effects models · Pregnancy

\section{Introduction}

The effects of childbirth on new parents' life satisfaction have been analysed extensively over decades, often finding that the costs and benefits of children tend to offset each other (Hansen 2012; Nelson et al. 2014). Little research exists, however, on the consequences of

Björn Huss

b.huss@ish.uni-hannover.de

Sociology Department, Leibniz University Hannover, Schneiderberg 50, 30167 Hannover, Germany 
alternative pregnancy outcomes on well-being, although a significant proportion of pregnancies result in abortion, either spontaneous (also called miscarriage) or induced. Worldwide, about one in five pregnancies ends in induced abortion and the risk of miscarriage in known pregnancies is roughly 11-22\% (Ammon Avalos et al. 2012; Sedgh et al. 2012). The consequences of alternative pregnancy outcomes on women's well-being are therefore of substantial interest to researchers in various fields.

Past research on pregnancy termination often focused on mental health outcomes. For many women, miscarriage is accompanied by negative psychological consequences such as depression and grief, anxiety, and post-traumatic stress symptoms (Kersting and Wagner 2012; Kong et al. 2013; Swanson et al. 2009; Gravensteen et al. 2018; Gold et al. 2016). In some studies, induced abortion has also been associated with negative consequences such as anxiety, depression, and even suicidal behaviour (Cougle et al. 2003, 2005; Fergusson et al. 2006; Reardon and Cougle 2002). These findings, however, are subject to a number of serious methodological and interpretative flaws (see, e.g., Steinberg and Russo 2008; Steinberg and Rubin 2014). Most investigations-including systematic literature reviews-have concluded that the relative risk of mental health problems does not increase in response to induced abortion (e.g., Biggs et al. 2017, 2018; Taft and Watson 2008; National Collaborating Centre for Mental Health 2011; Major et al. 2008). Charles et al. (2008) summarised that negative long-term effects of induced abortion on mental health were found almost exclusively in poor-quality studies, while high-quality studies did not provide support for this relationship.

Although several investigations have focused on the psychological outcomes of induced abortion and miscarriage, most of them used a pathogenic approach by considering mental health as a dichotomy, separating health and illness (e.g., depression vs. no depression). Examining the consequences of pregnancy termination from a salutogenic perspective, however, allows an analysis of psychological outcomes (e.g., using a continuous measure of life satisfaction) independently of the categories "health" and "illness" (Antonovsky 1988). Despite a strong correlation between life satisfaction and mental illness (e.g., Touburg and Veenhoven 2015; Rissanen et al. 2011), they are not at opposite ends of the same scale: Poor life satisfaction is not necessarily accompanied by a psychological disease with a demand for treatment (Westerhof and Keyes 2010).

To my knowledge, only three longitudinal studies have explicitly examined the association between induced abortion and overall life satisfaction (Biggs et al. 2014, 2017; Broen et al. 2005), two have studied the association between miscarriage and overall life satisfaction (Broen et al. 2005; Schwerdtfeger and Shreffler 2009), and two more the association between miscarriage and relationship satisfaction (Gravensteen et al. 2018; MekoshRosenbaum and Lasker 1995). This is a surprising research gap in view of the finding that life satisfaction and other dimensions of subjective well-being are strongly related to health and longevity and are predictors of decision-making in family and career contexts (Diener and Chan 2011; Luhmann et al. 2013). Furthermore, neither of these studies provided any information on satisfaction measures before the given event. Adjusting for pre-event satisfaction is, however, a major predictor of future well-being and consequently crucial in order to disentangle the causal relationship between pregnancy termination and well-being (Charles et al. 2008).

Life satisfaction is relatively stable over the life course but can change permanently following major life events (Luhmann et al. 2012). The aim of this study was to disentangle the causal relationship between pregnancy termination-either intentional or unintendedand women's overall and domain-specific life satisfaction. To do so, I used longitudinal data from Germany to examine whether (1) pre-pregnancy measures correlate with the risk 
of pregnancy termination (induced abortion, miscarriage) and whether (2) a termination of pregnancy is accompanied by substantial changes in subjective well-being over the life course.

\section{Background}

Induced abortion and miscarriage are similar in that both events represent a termination of pregnancy. Moreover, handling these alternative pregnancy outcomes involves the same actors, institutions, and counselling services in the health care system (e.g., Curtis 2007), and the persons affected are often subject to social prejudices, taboos, and stigmas (Sundstrom 2014; Kelley and Trinidad 2012; Gold et al. 2012). The events, however, differ in important respects. An induced abortion is preceded by a decision and is often the consequence of an unintended pregnancy, whereas miscarriage usually occurs suddenly and involuntarily and is thus an unexpected life event following a planned or unplanned pregnancy. Aiming to account for the causal relationship between abortion or miscarriage and women's subjective well-being, these differences require a nuanced theoretical consideration of both alternative pregnancy outcomes.

\subsection{Induced Abortion and Well-Being}

The reasons for undergoing an induced abortion are diverse and vary worldwide (Biggs et al. 2013; Finer et al. 2005; Finer and Henshaw 2003): Women have abortions for personal reasons (e.g., relationship problems, financial costs of child-rearing, wanting to postpone motherhood to a more suitable time), societal reasons (e.g., disapproval of single motherhood, sex-selective abortions, population control), and health-related reasons (e.g., potential risk to maternal or fetal health). What all these situations have in common is that an induced abortion is a planned and known event. Except under specific circumstances, such as pregnancy termination forced by a third party, induced abortion is usually the consequence of a voluntary and conscious decision by the pregnant woman.

The decision itself can perhaps be best understood within the framework of a subjective expected utility theory (Savage 2012): The pregnant woman uses the available information and her individual preferences to evaluate the consequences of having the baby versus those of having an abortion. She selects the option that is presumed to maximise her utility based on subjective expectations regarding the pros and cons of (not) having an abortion and the probabilities of each outcome. The father of the unborn child and other close relatives are usually involved in the decision. The decision is seldom made spontaneously and the woman is, to a certain extent, mentally prepared. Nevertheless, the process of deciding to have an abortion might be difficult and burdensome, and the termination of pregnancy may have unexpected effects on the individual's well-being (Miller et al. 1998).

Two conceptual frameworks dominate the literature on the consequences of induced abortion: the trauma theory (1) considers abortion as a traumatic experience caused, among other things, by witnessing the death of the unborn child (e.g., Coleman et al. 2005; Speckhard and Rue 1992). According to the common-risk-factors approach (2), in contrast, "third variables" rather than the abortion itself are responsible for subsequent mental health problems and poor well-being (Steinberg and Finer 2011). For example, since in most cases an induced abortion is preceded by an unintended pregnancy (Horvath and Schreiber 2017; Biggs et al. 2013), which is in turn associated with various negative consequences for 
women's mental health (Coleman 2006; Grussu et al. 2005; Korenman et al. 2001), this perspective views an unwanted pregnancy as the crucial life event that negatively affects women's well-being (e.g., Steinberg and Rubin 2014). Following this rationale, the decision to abort is a strategy to cope with the consequences of unintended pregnancies rather than the cause of poor well-being. However, even from this perspective it is assumed that an induced abortion can produce additional stress in itself, but that this stress does not necessarily lead to negative psychological experiences for women (Major et al. 2009). Recent studies have even shown that—even years after the event— the decision to abort is often accompanied by feelings of relief and is regretted only by a minority of women (Rocca et al. 2020). Undergoing an abortion can thus either intensify or reduce the negative psychological consequences of an unwanted pregnancy. From a methodological point of view, it is difficult to differentiate between these two potential causes of decreasing post-abortion life satisfaction since both events (unwanted pregnancy and subsequent abortion) are usually closer in time than the interview intervals in panel surveys. Furthermore, the literature supporting trauma theory assumptions suffers from serious methodological and interpretational weaknesses. These studies often use inappropriate comparison groups and analysis methods, fail to control for important confounding factors, are prone to sampling bias, and produce non-reproducible results, so must therefore be interpreted with caution (for an overview, see Steinberg and Rubin 2014; Steinberg and Russo 2008; Major et al. 2009).

The legal conditions of pregnancy termination might also affect how women's subjective well-being responds to abortion. In Germany, induced abortion is subject to strict regulations and only permitted under specific conditions (according to $\S 218 \mathrm{a}$ of the German Criminal Code): First, via consulting services that offer abortions within the first 12 weeks of pregnancy; of the affected women, approximately $96 \%$ used this route. Second, when due to medical necessity; about $4 \%$ of abortions take place for this reason. Lastly, as a result of rape; only a very few women make use of abortion services for this reason. (Federal Statistical Office of Germany 2020). Furthermore, medical practitioners can refuse abortions due to ethical concerns and are also not allowed to advertise this procedure (see German Pregnancy Conflict Law and § 219a of the German Criminal Code). As a consequence of such strict regulations, women might feel stigmatised, which is often accompanied by negative consequences for psychological well-being (Hatzenbuehler et al. 2013).

When analysing the relationship between induced abortions and subjective well-being within the life course, it is necessary to focus on both the consequences and the preconditions of pregnancy termination. Studies have shown that women who have had abortions are more likely to have had prior mental-health problems which, in turn, predicted postabortion mental health issues (Steinberg and Finer 2011; Steinberg et al. 2014). Because mental health strongly correlates with subjective well-being (Touburg and Veenhoven 2015), I hypothesised that women who choose abortion show lower pre-event levels of overall and domain-specific life satisfaction than women who carry their pregnancies to term. This thesis is accompanied by the assumption that selection of abortion is not ran$\mathrm{dom}$, but is prone to various pre-event confounding factors such as well-being or pregnancy intentions (Steinberg et al. 2014; van Ditzhuijzen et al. 2013; Horvath and Schreiber 2017).

The few studies to date that have examined the causal consequences of induced abortion on overall life satisfaction are limited in their explanatory power. One study examined the effects of abortion on overall life satisfaction but included abortion in the same category as other presumably negative life events (Suh et al. 1996). In this study, it remains unclear whether changes in overall life satisfaction can be attributed to abortion or other life events. Two studies claimed to report the relationship between abortion and well-being but in fact examined changes in self-esteem rather than life satisfaction (Major et al. 2000; Russo and 
Dabul 1997). However, three studies measured changes in women's overall life satisfaction up to five years after having an abortion, and were therefore able to analyse adaption to the event (Biggs et al. 2014, 2017; Broen et al. 2005). All three showed that overall life satisfaction rises (slightly) following abortion. These studies, unfortunately, lack information on levels of life satisfaction before termination of pregnancy. Because individuals often respond initially to life events but quickly return to pre-event satisfaction levels (Headey 2007; Lucas 2007), rising life satisfaction after abortion might merely reflect an adjustment to (unobserved) satisfaction declines in response to unintended pregnancies and abortion. I therefore hypothesised that abortion is accompanied by a short-term decline in overall life satisfaction, followed by a process of adaptation.

I did not find any studies examining the impact of abortion on dimensions of subjective well-being other than overall life satisfaction. Considering changes in domain-specific well-being might, however, improve our understanding of how women respond to unintended pregnancies that result in induced abortion. Furthermore, bottom-up approaches consider overall life satisfaction an additive combination of satisfaction in different domains of life, such as family satisfaction, financial satisfaction, and satisfaction with social networks (Headey et al. 1991). Induced abortion is stigmatised in some sectors of society-in particular by conservative politicians, media, and religious groups (Major et al. 2009). Experiencing abortion stigma might therefore be associated with social exclusion and, as a consequence, with dissatisfaction regarding social networks and the quality of leisure (Hanschmidt et al. 2016). The decision to abort might further be accompanied by conflicts with the partner and other family members which could result in declining satisfaction with family life and the relationship (Major et al. 1997; Huss and Pollmann-Schult 2020). On the other hand, a partner can provide valuable resources and support that may help to cope with the situation. Social support by a partner or other close relatives might therefore strengthen emotional bonds within the relationship (Balderrama-Durbin et al. 2013).

\subsection{Miscarriage and Well-Being}

Miscarriage is defined as the natural death of an embryo or fetus before it is able to survive independently (Hurt et al. 2011). Prevalence of diabetes, obesity, thyroid problems, drug and alcohol abuse, smoking, advanced age, and previous miscarriages are the main risk factors for miscarriage (Oliver and Overton 2014; Garćia-Enguídanos et al. 2002).

Although avoiding these risk factors reduces the probability of miscarriage, pregnant women are usually unprepared for an unwanted termination of pregnancy. Studies on the psychological consequences of critical life events have shown that some significant incidents have a sustained positive or negative impact on life satisfaction (Suh et al. 1996). According to a prevailing theory of well-being, the (revised) set point or dynamic equilibrium theory, however, individuals adapt to most life events and (largely) return to pre-event levels of life satisfaction after a certain period of time (Headey and Wearing 1989; Headey 2007; Lucas 2007).

I only found two studies examining the effects of miscarriage on overall life satisfaction and two more examining those on relationship satisfaction. In a univariate, cross-sectional analysis, Schwerdtfeger and Shreffler (2009) found that nulliparous women and mothers who experienced pregnancy loss (miscarriage or stillbirth) showed lower levels of overall life satisfaction than mothers who have never experienced a pregnancy loss. Broen et al. (2005), in contrast, conducted a longitudinal analysis and found rising levels of women's 
overall life satisfaction in a period of time after miscarriage. Neither of these studies, however, informs us about levels of life satisfaction before pregnancy loss. Because several studies have documented post-traumatic symptoms following miscarriage, I hypothesised that women experience at least initial declines in overall life satisfaction following miscarriage (Engelhard 2004; Gold et al. 2016).

Neither of the two studies on relationship satisfaction found substantial differences between women who had suffered a (previous) pregnancy loss and those who had experienced (previous) live births, or women who have never given birth (Gravensteen et al. 2018; Mekosh-Rosenbaum and Lasker 1995). One of the two, however, used a very selective sample of pregnant women (Gravensteen et al. 2018). Becoming pregnant again might improve relationship satisfaction and consequently bias the effects of pregnancy loss. Other investigations of the relationship consequences of (recurrent) miscarriage have shown that couples often report problems with sexuality and a greater hazard of union dissolution following termination of pregnancy (Serrano and Lima 2006; Gold et al. 2010). Considering these inconsistent findings, I did not propose a hypothesis on whether relationship satisfaction declines after miscarriage. Finally, I hypothesised that declines occur in women's leisure satisfaction and satisfaction with social contacts after miscarriage, as many women who experienced a miscarriage showed less social interaction as well as reduced personal comfort levels, and tended to avoid leisure activities (Speckhard 1997).

\section{Methods}

\subsection{Data and Sample}

This study used data from eleven waves of the German Panel Analysis of Intimate Relationships and Family Dynamics (pairfam). Pairfam is a nationally representative longitudinal sample of respondents in three birth cohorts, born in 1971-73, 1981-83, and 1991-93, ${ }^{1}$ who have been interviewed annually since 2008 (Brüderl et al. 2020; Huinink et al. 2011). The response rate gained from personal and paper and pencil interviews in the first wave was $37 \%$, resulting in a sample size of 12,402 respondents in 2008 . By collecting data from different members of the family or couple (multi-actor design), pairfam provides substantial information regarding intimate relationships, fertility plans and behaviour, and wellbeing in different domains of life.

The unit of analysis was 5,531 reproductive-age women aged 16-45 years who participated in the survey at least twice. Parts of the analyses were restricted to women who became pregnant during the observation period, resulting in subsamples of participants with different pregnancy outcomes: 214 women (3.9\% of all respondents) whose pregnancy ended in induced abortion, 331 women (5.9\%) whose pregnancy ended in miscarriage, and (for parts of the analysis) a control group of 1156 women (20.9\%) who carried their pregnancies to term. For women who reported more than one pregnancy termination, I only used information on the first observed abortion or miscarriage. The participants were observed for 6.9 years on average (37,004 person-years). While information on overall life satisfaction, social contact satisfaction, leisure satisfaction, and family satisfaction

\footnotetext{
1 In wave eleven, the pairfam study was extended by a further birth cohort (2001-2003). However, since only one wave is available for this cohort so far, it was not included in the present study.
} 
was gathered from all respondents, only partnered women provided information on relationship satisfaction.

Underreporting of induced abortion is widespread in social surveys (Jones and Kost 2007). Pairfam, however, provides information of more than 18 abortions per 100 live births whereas the official data of the Federal Statistical Office of Germany vary between 13 and 17 abortions per 100 live births (Federal Statistical Office of Germany 2020). The proportion of women with induced abortion in the pairfam data is thus comparable to that in the official register data. Most of the variables under analysis had very few missing values, but roughly $7 \%$ of the respondents did not provide information on abortion or miscarriage. Research has shown that certain population groups (e.g., those with low income, those with a migration background or those who have had an abortion in their $20 \mathrm{~s}$ ) are the least likely to report their experience of abortion in social surveys (Jones and Kost 2007). It is therefore possible that these people are slightly underrepresented in the sample studied. In an additional analysis (not shown), I used a multiple imputation approach to compare different methods of dealing with missing data. As the results were similar to those when using listwise deletion, I decided to drop person-years with missing data on any of the variables under analysis.

\subsection{Measures}

\subsubsection{Dependent Variables}

Information about overall life satisfaction and satisfaction with four different domains of life was gathered on 11-point scales. Overall life satisfaction was measured with the question "All in all, how satisfied are you with your life currently?" The variables measuring social contact satisfaction, leisure satisfaction, and family satisfaction were based on the question "How satisfied are you with the following domains in your life?" with a separate response scale for each item, and the variable relationship satisfaction was measured with the question "All in all, how satisfied are you with your relationship?" The response scales of all five variables ranged from 0 (very dissatisfied) to 10 (very satisfied). Various studies showed that single-item measures of life satisfaction and other domains of psychological well-being show a satisfactory level of reliability (Cheung and Lucas 2014; Diener et al. 2013; Lucas and Donnellan 2012; Wanous et al. 1997).

\subsubsection{Pregnancy Termination Variables}

The key predictors for changes in these outcomes were pregnancy termination and the elapsed time following the event. In each wave, respondents were asked whether they had had an induced abortion or miscarriage since the last interview. I identified the year of induced abortion or miscarriage and the amount of time before and after both events. Both short- and long-term changes in well-being following induced abortion and miscarriage were assessed using three variables each: (1) a binary variable distinguishing between all pre-event observations and all post-event observations to capture initial changes in wellbeing; (2) a linear duration variable counting the years since abortion or miscarriage; and (3) a squared duration variable. Preliminary analyses have shown that this form of curvilinear adaptation reflects the data most adequately (compared to linear or cubic models). These variables allowed me to account for both the initial impact of pregnancy termination within the life course and patterns of adaptation to pregnancies that result in induced 
abortion or miscarriage. The individual number of waves before and after termination of pregnancy varied depending on the year of the event as well as panel attrition.

\subsubsection{Pre-Pregnancy Confounders}

To categorise possible selection criteria into different pregnancy outcomes (live birth, induced abortion, miscarriage) and to explore the extent to which pre-event well-being can predict post-event well-being, I first considered the pre-event values of the outcomes, and I used the last observation before pregnancy to capture pre-event well-being. Since research has shown that the pregnancy preceding an induced abortion is often unplanned (see Steinberg and Rubin 2014; Biggs et al. 2013), I also included measures of pre-termination pregnancy intentions. Information on pregnancy intention was based on the survey question "Have you tried to become pregnant since the last interview?", resulting in a binary variable distinguishing between women with a planned/expected pregnancy and women with an unplanned/unexpected pregnancy. Although pregnancy intentions can change over time (e.g., Ralph et al. 2020; Rocca et al. 2019), I assume that they did not change significantly in the brief interval between the last measurement before pregnancy and the onset of pregnancy. Finally, the analysis used a number of socio-demographic factors that act as risk factors for selection into pregnancy termination (see Taft and Watson 2008; Steinberg and Russo 2008; Charles et al. 2008): (1) respondents' age when becoming pregnant was captured using a variable with the categories " $<20$ years", "20-29 years", "30-39 years", and "> 39 years"; (2) with regard to educational attainment, I have distinguished between "lower secondary education", "higher secondary education", "post-secondary/tertiary education", and "no degree/currently enrolled"; (3) the employment status was divided into "full-time employed", "part-time employed", "non-employed, and "school / vocational training"; (4) the partnership status was captured using two binary variables indicating whether or not the respondent was partnered or married; (5) and the number of children in the household was measured by a metric variable.

\subsubsection{Time-Varying Controls}

In the longitudinal analyses I used a within-person approach, which statistically adjusts for all time-invariant confounders (such as pre-event satisfaction and pregnancy intentions). Regarding time-varying variables, however, research has shown that different covariates may affect how women adapt following pregnancies that result in induced abortion or miscarriage: Since the association between psychological well-being and age is U-shaped (Blanchflower and Oswald 2008), I controlled for respondents' current age (aggregated to categories, see Table 1). Women of reproductive age are likely to become pregnant again, which may not only influence the adaptation to pregnancy termination, but also causes changes in well-being independent from the previous termination (Steinberg and Russo 2008; Huss and Pollmann-Schult 2020). The analysis consequently included time-varying controls on (the number of) post-event live births and pregnancy terminations. Because adaptation to pregnancy termination might furthermore be driven by the presence of a stable relationship (Steinberg and Finer 2011; Charles et al. 2008; Klier et al. 2002), I controlled for post-event changes in relationship status and marital status. Finally, wave 
Table 1 Descriptive characteristics for outcome variables and covariates

\begin{tabular}{|c|c|c|c|c|c|c|c|c|}
\hline & \multirow{2}{*}{\multicolumn{2}{|c|}{ Full sample $^{\mathrm{a}}$}} & \multicolumn{6}{|c|}{ Pregnancy outcome samples ${ }^{b}$} \\
\hline & & & \multicolumn{2}{|c|}{$\begin{array}{l}\text { Abortion } \\
\text { sample }\end{array}$} & \multicolumn{2}{|c|}{$\begin{array}{l}\text { Miscarriage } \\
\text { sample }\end{array}$} & \multicolumn{2}{|c|}{$\begin{array}{l}\text { Live birth } \\
\text { sample }\end{array}$} \\
\hline & M & SD & M & $\mathrm{SD}$ & M & $\mathrm{SD}$ & M & SD \\
\hline \multicolumn{9}{|l|}{ Outcome variables } \\
\hline Overall life satisfaction & 7.57 & 1.68 & 7.07 & 2.05 & 7.51 & 1.78 & 7.71 & 1.65 \\
\hline Social contact satisfaction & 7.65 & 1.97 & 7.25 & 2.26 & 7.32 & 2.12 & 7.29 & 2.02 \\
\hline Leisure satisfaction & 6.77 & 2.17 & 6.21 & 2.33 & 6.42 & 2.23 & 6.24 & 2.19 \\
\hline Family satisfaction & 8.37 & 1.79 & 7.86 & 2.19 & 8.30 & 1.94 & 8.52 & 1.68 \\
\hline Relationship satisfaction ${ }^{\mathrm{c}}$ & 7.80 & 2.17 & 7.23 & 2.62 & 7.76 & 2.24 & 7.76 & 2.10 \\
\hline \multicolumn{9}{|l|}{ Covariates } \\
\hline Pregnancy intentions $(1=$ yes $)$ & 0.09 & 0.28 & 0.11 & 0.32 & 0.31 & 0.47 & 0.20 & 0.40 \\
\hline Number of children & 0.93 & 1.10 & 1.09 & 1.11 & 1.12 & 1.05 & 1.64 & 1.05 \\
\hline Partnered ( $1=$ yes $)$ & 0.54 & 0.50 & 0.50 & 0.50 & 0.74 & 0.44 & 0.79 & 0.41 \\
\hline Married (1=yes) & 0.39 & 0.49 & 0.31 & 0.46 & 0.54 & 0.50 & 0.63 & 0.48 \\
\hline \multicolumn{9}{|l|}{ Age } \\
\hline$<20$ years & 0.14 & & 0.10 & & 0.03 & & 0.02 & \\
\hline 20 to 29 years & 0.31 & & 0.35 & & 0.29 & & 0.23 & \\
\hline 30 to 39 years & 0.36 & & 0.40 & & 0.49 & & 0.57 & \\
\hline$>39$ years & 0.19 & & 0.15 & & 0.19 & & 0.19 & \\
\hline \multicolumn{9}{|l|}{ Educational attainment } \\
\hline Lower secondary education & 0.09 & & 0.18 & & 0.10 & & 0.08 & \\
\hline Higher secondary education & 0.45 & & 0.43 & & 0.44 & & 0.42 & \\
\hline Post-secondary / tertiary education & 0.45 & & 0.35 & & 0.45 & & 0.47 & \\
\hline No degree / currently enrolled & 0.01 & & 0.04 & & 0.02 & & 0.02 & \\
\hline \multicolumn{9}{|l|}{ Employment status } \\
\hline Full-time employed & 0.32 & & 0.31 & & 0.35 & & 0.24 & \\
\hline Part-time employed & 0.28 & & 0.27 & & 0.26 & & 0.35 & \\
\hline Non-employed & 0.17 & & 0.25 & & 0.31 & & 0.36 & \\
\hline School / vocational training & 0.23 & & 0.17 & & 0.08 & & 0.05 & \\
\hline$n$ (individuals) & 5,331 & & 214 & & 331 & & 1,156 & \\
\hline$N$ (person-years) & 37,004 & & 1,812 & & 2,868 & & 10,054 & \\
\hline
\end{tabular}

Average levels (M) and Standard Deviations (SD) of all available person-years before and after a pregnancy

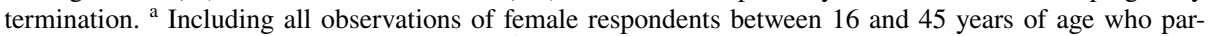
ticipated in the pairfam study at least twice. ${ }^{b}$ Samples restricted to women observed across the transition to either induced abortion, miscarriage, or live birth. ${ }^{\mathrm{c}}$ Estimated for 3,644 partnered women (full sample), 158 partnered women (abortion sample), 299 partnered women (miscarriage sample), and 1,053 partnered women (livebirth sample)

dummies were added to all longitudinal models to control for potential period effects (e.g., idiosyncratic pre-interview events affecting the outcome; see Brüderl and Ludwig 2015).

Table 1 shows descriptive statistics for both outcome variables and covariates. The table provides average levels of all available person-years for the full sample of 
reproductive-age women in the pairfam study and for the three analytic samples of women observed across the transition to induced abortion, miscarriage, or live birth.

\subsection{Analytical Strategy}

The aim of this analysis was to disentangle the causal relationship between alternative pregnancy outcomes (induced abortion, miscarriage) and satisfaction in different domains of life. The existing research offers two interpretations that are not necessarily mutually exclusive: (a) differences in well-being compared to other women can be attributed to the consequences of pregnancy termination or an accompanying unintended pregnancy and (b) women with specific levels of well-being are more likely to experience a pregnancy termination. Given these competing theoretical models and the methodological weaknesses of many existing studies on this topic, the present investigation is conducted in two carefully considered analytical steps.

In the first step, I aimed to identify selection bias in induced abortion and miscarriage that that may predict low post-event well-being. This was done by examining whether women with alternative pregnancy outcomes showed systematic differences in pre-event measures compared to other women. It was therefore necessary first to find a suitable comparison group. Or, from a more contrafactual perspective (see Morgan and Winship 2015), one could ask: What would be an alternative scenario to induced abortion or miscarriage? Since most pregnancies end in live birth, I compared women who experienced induced abortion or miscarriage with those who gave birth (rather than directly comparing different forms of pregnancy termination that are assumed to be independent from each other). I did so by calculating pre-pregnancy standardised differences in means (standardised bias) for variables that are considered risk factors for selection into pregnancy termination (see Fig. 1). It is an effect size where the difference in covariate means between two groups is divided by the spread in means (Kainz et al. 2017; Stuart 2010). The literature often refers to a threshold value of 0.1 (e.g., Haukoos and Lewis 2015; Kainz et al. 2017). Standardised biases below this threshold indicate negligible imbalance whereas values exceeding this limit would point to considerable pre-event differences between both groups. A common approach in quasi-experimental designs is to conduct a propensity score matching that allows imbalances between groups to be dealt with (Morgan and Winship 2015). This study, however, aimed to identify causal consequences within the life course once selected into pregnancy termination rather than compensating for possible pre-event differences.

I therefore applied fixed effects linear regressions in the second step. Fixed effects regression adjusts for all of the respondents' observed and unobserved stable characteristics (Allison 2009). These models examine changes in women's well-being following pregnancy termination by investigating within-person changes rather than cross-sectional differences in levels of well-being between the subsamples. An advantage of this method is that it makes it possible to control for selection processes, for example, the risk of women with unintended pregnancies or low levels of well-being having an induced abortion. Because the participants (or rather their changes in satisfaction compared to pre-event levels) serve as their own control groups by adjusting for all time-constant confounders during the observation period, fixed effects models do not require a control group of women who have had a live birth. The longitudinal analysis consequently included only time-varying controls. Changes in these variables, however, are often-vice versa-influenced by pregnancy termination (for example, having experienced a miscarriage is associated with increased odds of union dissolution; see Shreffler et al. 2012). Including these covariates 


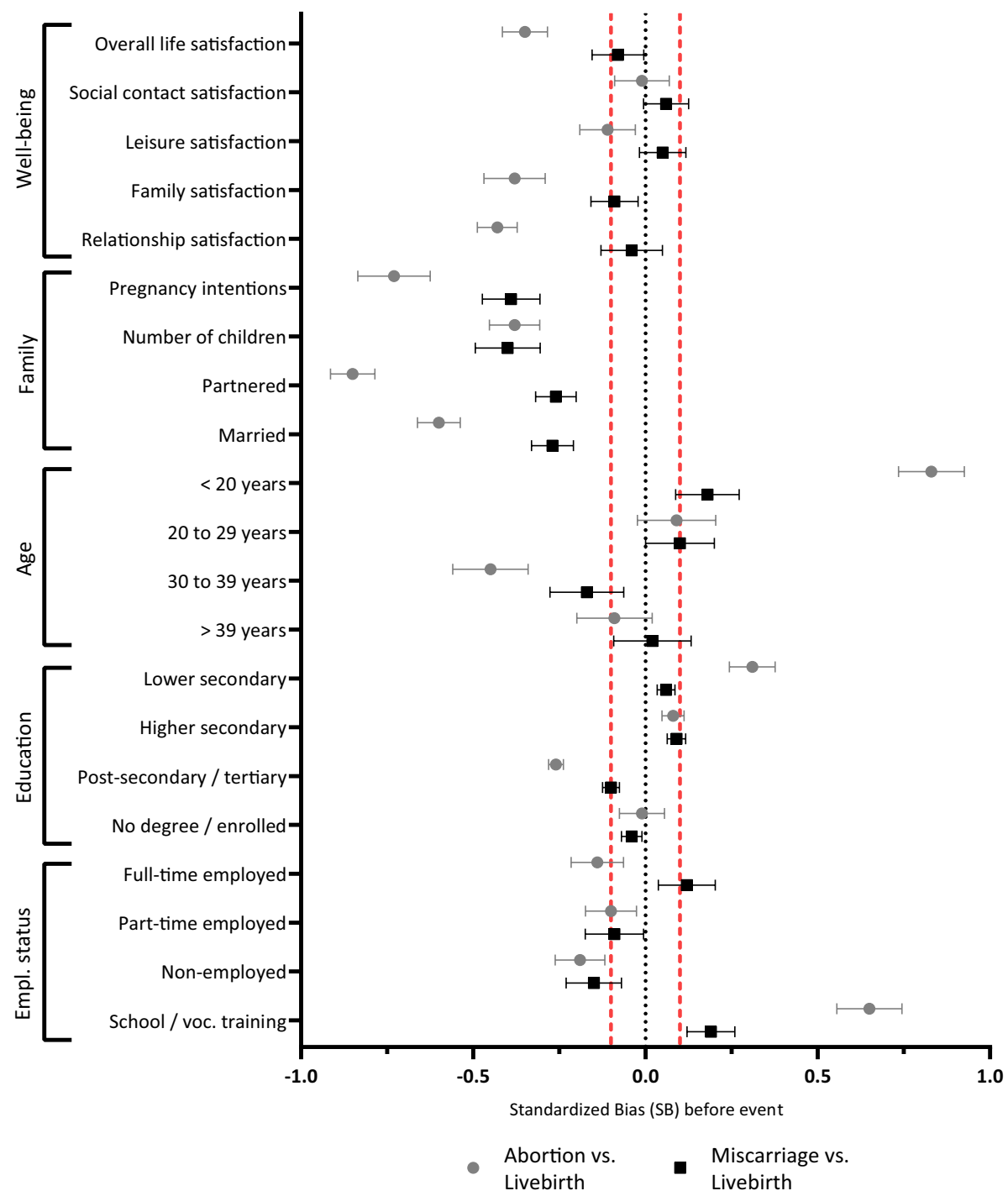

Fig. 1 Standardised pre-event difference in means: abortion vs. live birth and miscarriage vs. live birth

restricts the main effects to those who did not experience any changes in the respective variables (e.g., partnership status, number of subsequent births) after pregnancy termination by 'fixing' the living conditions of the women affected. To account for potential secondary effects, I have calculated two separate models for each outcome measure for women who had an induced abortion and for women who experienced a miscarriage: Models 1a to 5a in Tables 2 and 3 control only for age as a potential confounder, while models $1 \mathrm{~b}$ to $5 \mathrm{~b}$ additionally control for further time-varying variables. Small differences between models a and b would point to no or only minor secondary effects, while large differences could indicate significant secondary effects. All models were estimated with cluster-robust standard errors 


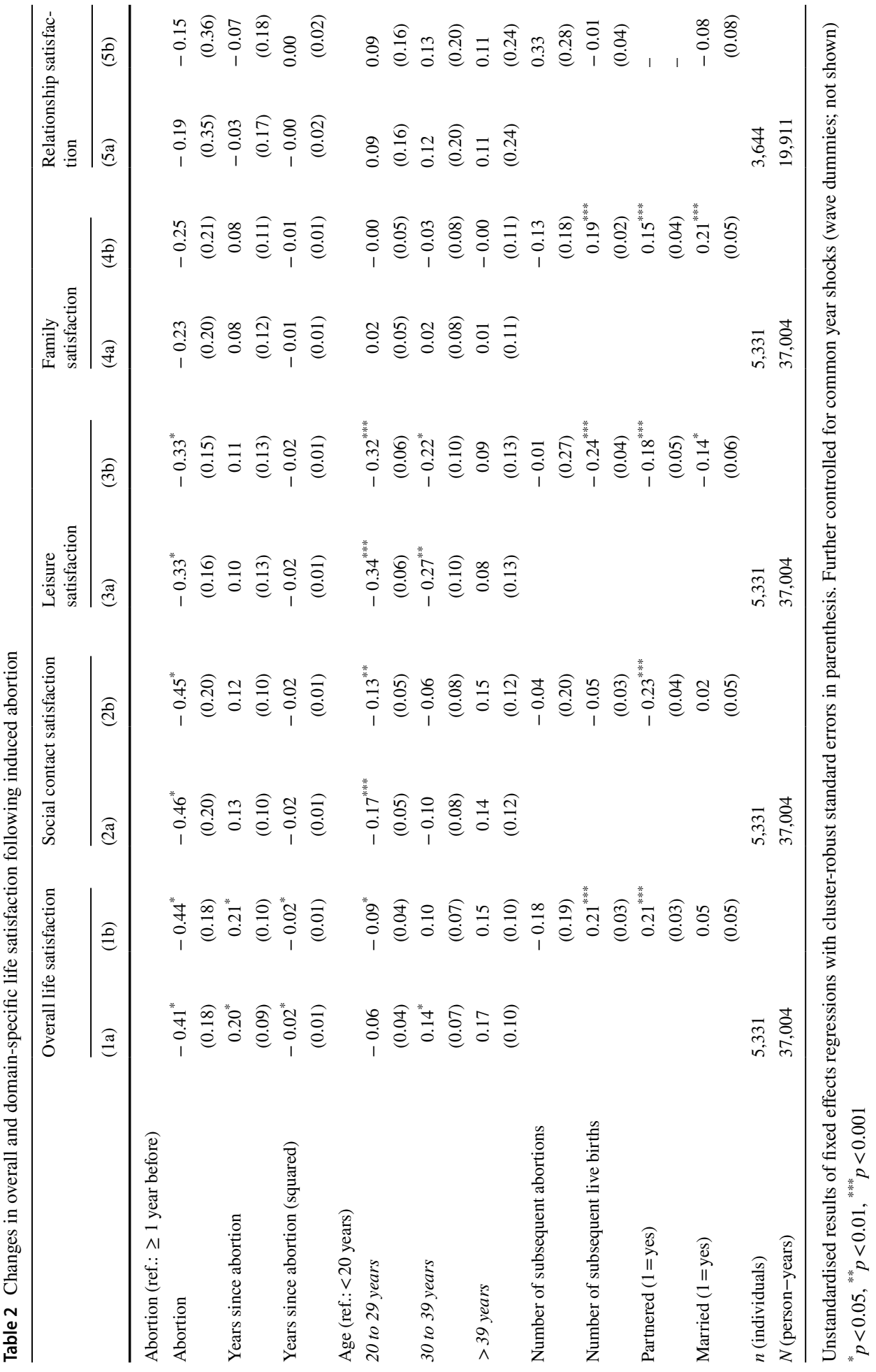


to correct for possible heteroscedasticity and serial correlation within clusters. Since they provide a control group for estimating common age effects, all models include observations of those reproductive-age women who did not became pregnant during the observation period (see also Brüderl and Ludwig 2015).

\section{Results}

\subsection{Pre-Event Levels}

The bias statistics are illustrated in Fig. 1. The standardised bias of the abortion sample is shown in grey, that of the miscarriage sample in black. Comparing pre-event measures of the outcome variables for women in the abortion sample and women in the live birth sample, the standardised mean differences exceeded the threshold of 0.1 in four of the five satisfaction measures considered. Except for social contact satisfaction, women in the abortion sample showed substantially lower pre-event levels in all domains of satisfaction and therefore differed substantially from those who gave birth. These findings provide support for the assumption that women with poor well-being are more likely to seek an induced abortion than women with higher levels of well-being. Studies that do not adjust for preevent levels when comparing the effects of abortions and live births are thus prone to yielding biased results. In addition to the pre-event satisfaction measures, the induced abortion sample differed substantially from the live birth sample in a number of other areas: women who underwent an induced abortion had significantly fewer pregnancy intentions before the event, were less likely to be partners or married and less likely to have had children than those who experienced a live birth. Differences were also found in terms of age, educational level, and employment status.

By contrast, women in the miscarriage sample did not differ systematically from women in the live birth sample regarding pre-event satisfaction measures. In neither of the satisfaction measures did the standardised mean differences exceed the threshold of 0.1 . I therefore found no evidence for the assumption that miscarriage is accompanied by lower pre-event satisfaction compared to live birth. Differences, however, were found in the sociodemographic and pregnancy-related covariates: Women in the miscarriage sample showed fewer pre-event pregnancy intentions and also a lower probability of having children, a partnership, or marriage than women in the live birth sample.

\subsection{Changes in Well-Being following Induced Abortion or Miscarriage}

The results of the fixed effects regressions for women who experienced pregnancy termination are presented in Table 2 (induced abortion) and Table 3 (miscarriage). I estimated separate models for overall life satisfaction (Models $1 \mathrm{a}$ and $1 \mathrm{~b}$ in Tables 2,3), social contact satisfaction (Models 2a and 2b), leisure satisfaction (Models 3a and 3b), family satisfaction (Models 4a and 4b), and relationship satisfaction (Models 5a and 5b). Each model shows within-person changes in the respective outcome measure following induced abortion or miscarriage (compared to pre-event satisfaction levels). The patterns of changes in well-being for women observed throughout the transition to pregnancy termination are furthermore illustrated in Fig. 2 (induced abortion) and Fig. 3 (miscarriage). Models a and b show, in general, very similar results for each outcome following induced abortion and miscarriage, suggesting that time-varying covariates are neither necessary to compensate 


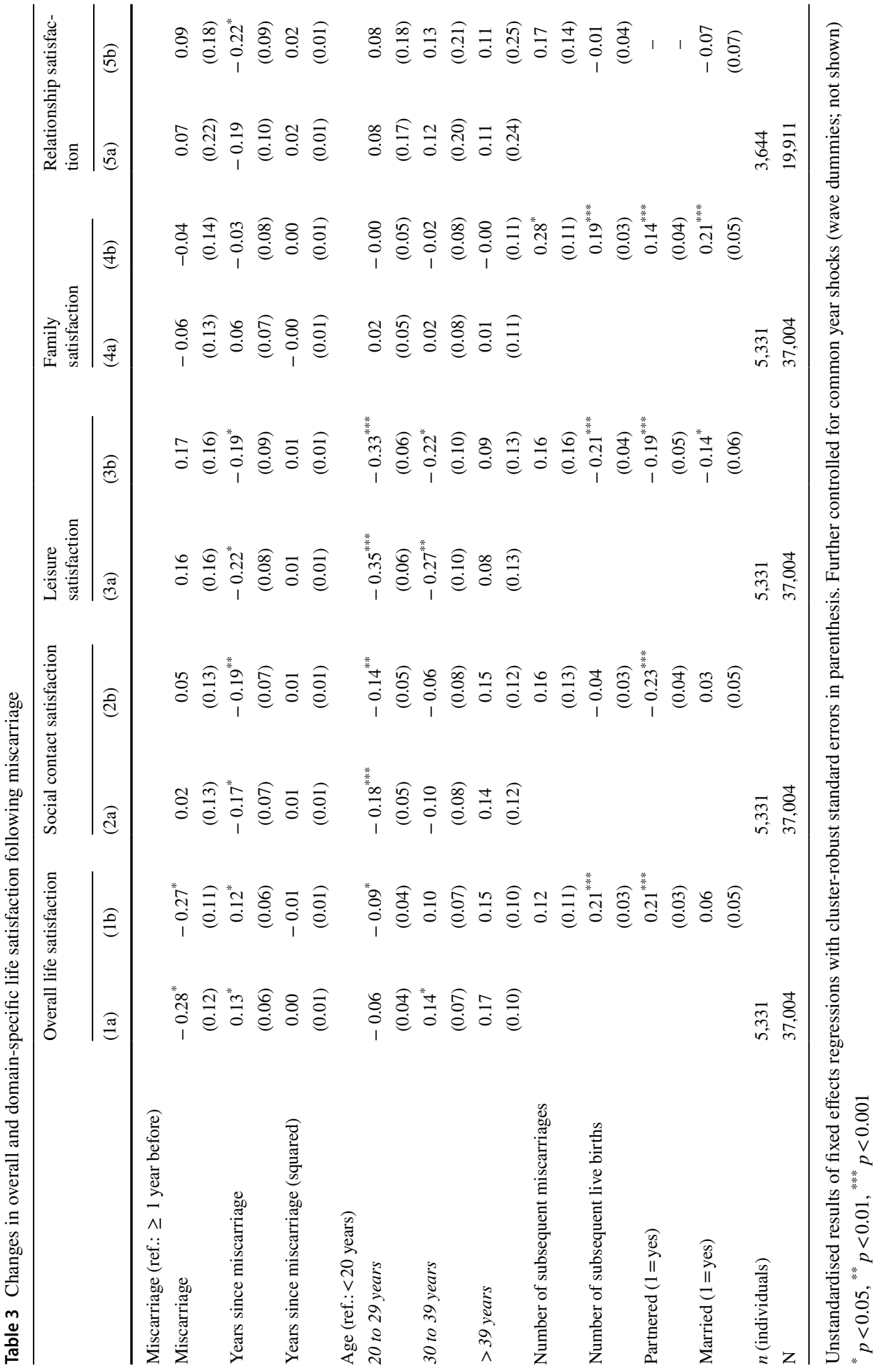


for bias nor cause significant secondary effects. For ease of reading, hereafter and in Figs. 2 and 3 , only the coefficients of models $1 \mathrm{~b}-5 \mathrm{~b}$ are presented.

\subsubsection{Results for Induced Abortion}

As can be seen in Models 1a and 1b (Table 2), women showed systematic initial declines in overall life satisfaction following induced abortion $(b=-0.44, p<0.05)$. The duration effect represented by the years since abortion was positive $(b=0.21, p<0.05)$ and the squared duration effect slightly negative $(b=-0.02, p<0.05)$, indicating curvilinear adjustment with decreasing marginal utility. Figure 2 shows that overall life satisfaction had almost fully recovered from the event in the years following the abortion.

Although a similar pattern was found for social contact satisfaction (Models 2a and 2b). Adjustment to initial declines $(b=-0.45, p<0.05)$, however, was weaker and insignificant $(b=0.12, p>0.05)$. As Fig. 2 shows, even five years after induced abortion, social contact satisfaction was significantly lower than before the event. I also found a negative initial effect for leisure satisfaction in Models $3 \mathrm{a}$ and $3 \mathrm{~b}(b=-0.33, p<0.05)$, followed by partial and insignificant adjustment $(b=0.08, p>0.05)$. Following abortion, women showed no significant initial or long-term changes in family and relationship satisfaction. However, since the main and duration coefficient for relationship satisfaction was negative, women in years 2 to 4 after abortion were significantly less satisfied with their relationship than before the event (see Fig. 2).

\subsubsection{Results for Miscarriage}

Models $1 \mathrm{a}$ and $1 \mathrm{~b}$ in Table 3 show that miscarriage was accompanied by initial declines in overall life satisfaction $(b=-0.27, p<0.05)$, followed by a process of adaptation in the subsequent years $(b=0.12, p<0.05)$. As was also the case following induced abortion, overall life satisfaction largely returned to pre-event levels in the years following miscarriage (see Fig. 3).

Although miscarriage was initially accompanied by only minor and insignificant increases in social contact satisfaction $(b=0.05, p>0.05)$, the following years showed considerable declines $(b=-0.19, p<0.01)$. Compared to pre-event levels, women showed significant and persistently lower social contact satisfaction in the long run (Fig. 3 and Models $2 \mathrm{a}$ and $2 \mathrm{~b}$ in Table 3). A similar picture emerges for leisure time satisfaction (Models $3 \mathrm{a}$ and $3 b$ ) and relationship satisfaction (Models 5a and 5b): there is a time lag after miscarriage following which distinct and permanent satisfaction losses occur (leisure satisfaction: $b=-0.19, p<0.05$; relationship satisfaction: $b=-0.22, p<0.05)$. Miscarriage was not accompanied by significant initial or long-term changes in family satisfaction. Since both the main and the time coefficient for satisfaction changes after miscarriage in Model $4 \mathrm{~b}$ were negative, however, women showed a lower long-term family satisfaction than before miscarriage (see Fig. 3).

\section{Discussion and Conclusion}

The aim of this study was to investigate the association between termination of pregnancy - either intended or unintended - and women's satisfaction in different domains of life. The results show that women demonstrated substantially lower pre-event satisfaction 
before having an induced abortion than before giving birth. As expected, pregnancy preceding induced abortion was furthermore significantly more often unintended than was pregnancy preceding live birth. Differences were also apparent in the presence of a partner and children. The findings emphasise that rather than being caused by the procedure itself, at least some aspects of poor well-being following an induced abortion may in fact reflect other abortion-related factors that place women "at risk" for intentional pregnancy termination (Major et al. 2009). If compared to other women, these factors are represented by poor pre-event levels of well-being. They furthermore show that "unwanted pregnancy and abortion do not occur in a social vacuum" (Major et al. 2009) but are embedded within a sociocultural context. This context moderates (a) how women respond to unintended pregnancies resulting in induced abortion and (b) the likelihood of deciding to have an induced abortion at all. In contrast to induced abortion, miscarriage was not associated with substantial differences in pre-event well-being compared to women who gave birth. These results indicate that overall and domain-specific life satisfaction did not affect the probability of experiencing a miscarriage. Differences were, however, found in other areas: Before miscarriage, as compared to live birth, women were less likely to have had children, a partner or pregnancy intentions.

Data analysis provided support for the hypothesis that women suffer temporarily following any termination of pregnancy: women showed declines in overall life satisfaction immediately after both induced abortion and miscarriage. In accordance with previous research, levels of overall life satisfaction increased in the subsequent years (Biggs et al. 2014, 2017; Broen et al. 2005). These increases, however, only reflect adjustments to preevent levels. Although most women largely recover following induced abortion or miscarriage, the initial post-termination decline in well-being can occasionally be accompanied by serious grief and distress. The literature offers two possible explanations for the temporary post-abortion declines in well-being: The affected women either suffer primarily (1) from the consequences of an induced abortion or (2) from the consequences of an unintended pregnancy (Steinberg and Rubin 2014). Assuming that pregnancy termination could provide a sense of self-efficacy and internal control, the decision to abort could therefore be a strategy for coping with an unintended pregnancy and possibly even facilitate adaptation to this event (see Major et al. 2009).

The results on domain-specific satisfaction offered deeper insights into the psychological consequences of both intentional and unintended termination of pregnancy. Although women experienced only temporary declines in overall life satisfaction after miscarriage, they became increasingly dissatisfied in various domains of life. Miscarriage resulted in substantially lower well-being in all domains of satisfaction than was the case before the event. These results emphasise that miscarriage is an unexpected incident with far-reaching consequences. It often represents the loss of a profoundly desired future child that heavily concerns several areas of life for those affected (Engelhard 2004). Ample research points to disparities between partners in dealing with the loss. Such disparities contribute to misunderstanding and conflicts, and might thus explain relationship and family dissatisfaction following miscarriage (Gold et al. 2010; Kersting and Wagner 2012). The declines in social contact satisfaction and leisure satisfaction may be a consequence of avoiding social and leisure activities following miscarriage. Involuntarily nulliparous women often regard childlessness as something negative and are concerned that others view them in an unfavorable light (Miall 1986; Rich et al. 2011). Because having a live birth is generally the idealised outcome of pregnancy, these women might perceive miscarriage as a kind of failure that intensifies their fears and might consequently tend to avoid social and leisure activities following pregnancy loss. 
0,10

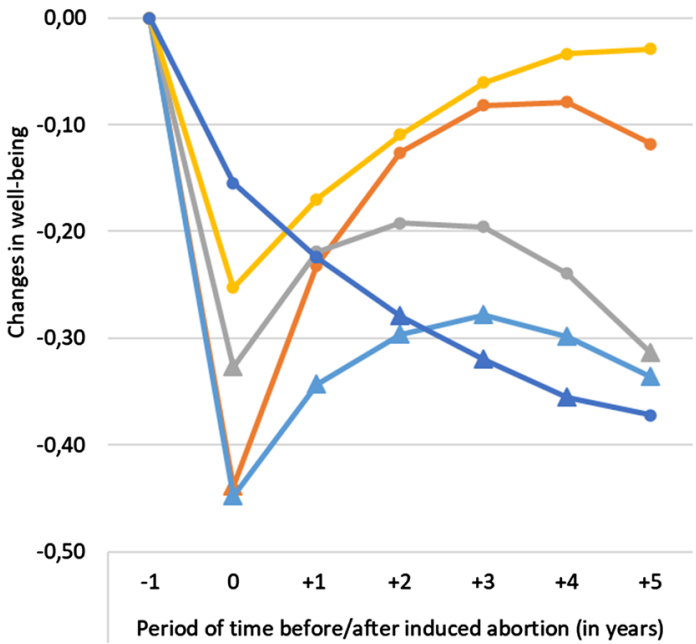

Fig. 2 Patterns of Changes in Well-Being after Induced Abortion. Results of fixed effects regressions from Table 2. Significant results of Wald chi2 statistics for testing the differences to pre-event well-being are marked with a triangle $(\mathrm{p}<0.05)$. Adjusted for changes in age, partnership status, marital status, subsequent live births, and subsequent abortions. Further controlled for common year shocks

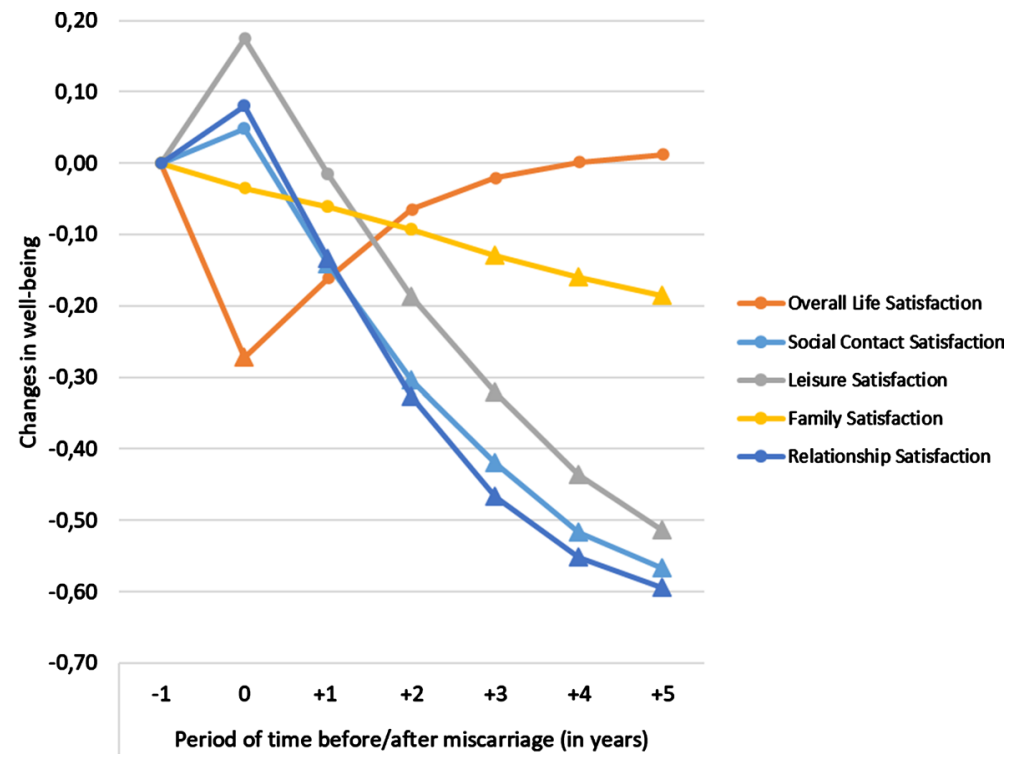

Fig. 3 Patterns of Changes in Well-Being after Miscarriage. Results of fixed effects regressions from Table 3. Significant results of Wald chi2 statistics for testing the differences to pre-event well-being are marked with a triangle. Adjusted for changes in age, partnership status, marital status, subsequent live births, and subsequent miscarriages. Further controlled for common year shocks 
Like miscarriage, induced abortion is also accompanied by decreasing satisfaction in many areas of life. Social contact satisfaction, leisure satisfaction, and relationship satisfaction were seen to be substantially lower following an abortion than prior to the event. Becoming increasingly dissatisfied in these areas might reflect perceptions of stigmatisation and shame due to strong anti-abortion attitudes. Existing research has shown that stigmatisation can create behavioural reactions such as social withdrawal or avoidance (Major and O'Brien 2005). Although this study did not explicitly examine this relationship, previous investigations indicate that poor social contact satisfaction following an induced abortion might be caused by stigmatisation processes that are accompanied by social withdrawal (Hanschmidt et al. 2016). Largely stable levels of satisfaction in overall well-being, however, can be seen as a result of a decision-making process. Women decide to abort because they perceive it as the most appropriate decision within their scope of action. Although the choice to have an abortion is certainly often a difficult decision with farreaching consequences, women might associate alternative courses of action (e.g., giving birth to an unwanted or disabled child) as having more negative consequences and therefore do not regret their decision (Major et al. 2009).

The findings on the consequences of abortion add evidence to the ongoing debate on the existence of any negative psychological long-term effects of induced abortion, which are often referred to as "post-abortion syndrome" (Cohen 2006; Stotland 2003). Although induced abortion is accompanied by dissatisfaction in some areas of life, my analysis did not provide support for this assumption, as women who experienced induced abortion did not fare either worse or better in overall satisfaction in the long run. These results are consistent with the notion of Bowles and colleagues that long-term psychiatric morbidity following intentional pregnancy termination is more the exception than the rule (Bowles et al. 2000). Furthermore, my analysis showed that even before terminating pregnancy, women who aborted were substantially less satisfied with life in almost all domains of well-being than other groups of women. Consequently, as induced abortion was shown to be rather a consequence than a cause of poor well-being, the term "pre-abortion syndrome" might be more appropriate than the term "post-abortion syndrome" to describe the relationship between induced abortion and well-being.

\subsection{Strengths and Limitations}

This study aimed to investigate the changes in overall and domain-specific life satisfaction following both induced and spontaneous abortion in a lifespan perspective. Strengths of my approach were the use of a multi-wave longitudinal sample and the clear focus on a salutogenic perspective, using satisfaction as an indicator of mental health. In these respects, it differs from most previous studies, which were based on small, very specific samples with short observation periods, frequently lacked pre-event information, and mixed several indicators of mental health, often by taking a pathogenic perspective (e.g., Broen et al. 2005; Bergant et al. 1997; Biggs et al. 2017). Nevertheless, a limitation of this study is that it focused on average changes in satisfaction following pregnancy termination, although research has shown that several factors such as social resources and the age of the women affected may moderate the adjustment to pregnancy termination and unintended pregnancies (e.g., Pereira et al. 2017; Rocca et al. 2013). In future research, it is crucial to identify which factors (e.g., personality, pre-event parenthood status, pregnancy intentions) and underlying mechanisms (e.g., support of family members or psychological services) affect how women respond to pregnancy termination. Accounting for more distinct groups, 
however, requires the availability of longitudinal data with sufficient case numbers. Unfortunately, the data used in this study provided only a limited number of participants that experienced a pregnancy termination during the observation period.

Another limitation relates to the measurement of pregnancy termination. Pairfam data did not provide information on the reasons for having an induced abortion. Because the circumstances of abortions for personal reasons differ in fundamental ways from those of medically indicated abortions, they might presumably be accompanied by different consequences for overall and domain-specific satisfaction. Furthermore, the data used in this study provided information on miscarriage (unintended termination of pregnancy prior to 20 weeks of gestation) but not on stillbirth (death of a fetus at or after the 20th week of gestation; NICHD 2019). As research has shown that mothers form attachments very early after conception, a later loss due to stillbirth entails a longer period of attachment and might therefore cause greater psychological distress than miscarriage (Gold et al. 2010; Kersting and Wagner 2012).

Finally, due to the large intervals between the interviews in the pairfam study, it is not possible to completely break down the causes of (temporary) post-abortion declines in well-being. Are these losses driven by the consequences of induced abortion? Or are they rather the result of an unintended pregnancy? If the latter is true, an abortion might be a form of coping with this unexpected event. This leads to the follow-up question of to what extent women who decide to abort fare better or worse than those who deliver their unintended child. Future post-abortion research should consequently aim at comparing women who have experienced unwanted pregnancies with different pregnancy outcomes (see also Coleman 2006; Steinberg and Rubin 2014).

Despite these limitations, this study gives profound insights into the changes that occur in overall and domain-specific life satisfaction after both intentional and unintended termination of pregnancy. It is the first study to look at the impact of induced abortion and miscarriage on different measures of satisfaction from a life course perspective.

\subsection{Implications for Research, Policy, and Practice}

The present study shifted attention to previously neglected dimensions of the relationship between pregnancy termination and well-being that, in turn, should be considered by practitioners, policymakers and future studies on this topic. First, poor well-being is not necessarily a consequence of induced pregnancy termination but often a precondition for selection into it. Researchers, particularly those who use cross-sectional data, should be cautious in using causal language when interpreting their data (see also, Charles et al. 2008). This finding furthermore indicates that preventive interventions should aim at maintaining and enhancing reproductive-age women's well-being in general and the well-being of unintentionally pregnant women in particular. Gynaecologists, for example, should be sensitised to the subject and talk to their patients systematically about potential reactions to unintended pregnancies. If necessary, they could provide information about counselling centres and psychotherapists who can provide psychological support in difficult life situations. This requires more efficient interdisciplinary cooperation than takes place currently on the part of the actors and institutions involved. In order to identify risk groups and to provide effective interventions, however, more evidence is needed regarding the living conditions and decision-making processes of dissatisfied women who unintentionally become pregnant (Finer et al. 2005; Finer and Henshaw 2003; Bankole et al. 1998). 
Second, both induced abortion and miscarriage are accompanied by temporary declines in overall well-being. These results shift attention to the need for immediate intervention that aims at reducing the short-term effects of pregnancy termination on well-being. The women affected should be the target of close support in the first one to three years after the event, which initially requires the comprehensive implementation and expansion of psychosomatic rehabilitation services as well as self-help groups. Furthermore, as research has shown that partners, friends and relatives can provide a valuable source of support in difficult life situations, they could also be involved within a process of dyadic and communal coping (see, Bodenmann 1997; Berg and Upchurch 2007; Helgeson et al. 2018). Since the psychosocial adjustment to pregnancy termination is a complex and multidimensional process that varies, for example, by age groups as well as social and familial resources (Pereira et al. 2017; Renner et al. 2014), preventive interventions should additionally be based on the individual situations of the affected women.

Third, both induced and spontaneous abortion are followed by substantially lower satisfaction with social contacts, leisure, and the relationships. We currently know too little about the underlying mechanisms and the data used in this study are inappropriate to provide substantial evidence on this issue. Are these declines driven by stigmatisation processes or the feelings of shame and guilt that may accompany pregnancy termination, as some researchers argue (Robinson et al. 2009)? If this is the case, policy interventions should aim to prevent social exclusion after pregnancy termination. In the German context, for example, strict abortion regulations according to the German Pregnancy Conflict Law and the German Criminal Code may increase anti-abortion attitudes in society and consequently lead to social exclusion of the women concerned (Hatzenbuehler et al. 2013). Prejudices and stigmatisation of miscarriages could further be reduced by additional education campaigns on female sexual health: Knowing that a miscarriage is a frequent pregnancy outcome that can affect any pregnant woman through no fault of her own could counteract prejudices and provide more social support for the women concerned (see also Curtis 2007). To gain deeper insights into the psychological processes that take place after alternative pregnancy outcomes and to provide suitable interventions, future research should aim at disentangling these uncertainties. This could be done through a salutogenetic approach (see Antonovsky 1988): What can be learned from those women who do not experience a significant deterioration in these domains of well-being after pregnancy termination? Are there specific resources that strengthen their resilience to these events?

Funding Open Access funding enabled and organized by Projekt DEAL.. Funding was provided by Deutsche Forschungsgemeinschaft (Grant No. 1569/4).

\section{Compliance with ethical standards}

Conflict of interest The author declares that he has no conflict of interest.

Informed Consent Informed consent was obtained from all individual participants included in the study.

Human or Animal Rights This article does not contain any studies performed by any of the authors in which animals were involved. 
Ethical Approval This study was entirely based on survey data of the pairfam study. All interviews in the pairfam study have been obtained in accordance with national ethical standards. Please visit the website of the pairfam study (https://www.pairfam.de/en/) for more information on ethical approvals.

Open Access This article is licensed under a Creative Commons Attribution 4.0 International License, which permits use, sharing, adaptation, distribution and reproduction in any medium or format, as long as you give appropriate credit to the original author(s) and the source, provide a link to the Creative Commons licence, and indicate if changes were made. The images or other third party material in this article are included in the article's Creative Commons licence, unless indicated otherwise in a credit line to the material. If material is not included in the article's Creative Commons licence and your intended use is not permitted by statutory regulation or exceeds the permitted use, you will need to obtain permission directly from the copyright holder. To view a copy of this licence, visit http://creativecommons.org/licenses/by/4.0/.

\section{References}

Allison, P. D. (2009). Fixed effects regression models (Quantitative applications in the social sciences, 07-160). Los Angeles: SAGE.

Ammon Avalos, L., Galindo, C., \& Li, D.-K. (2012). A systematic review to calculate background miscarriage rates using life table analysis. Birth defects research Part A, Clinical and Molecular Teratology, 94(6), 417-423. https://doi.org/10.1002/bdra.23014.

Antonovsky, A. (1988). Unraveling the mystery of health: How people manage stress and stay well (The Jossey-Bass health series). San Francisco: Jossey-Bass.

Balderrama-Durbin, C., Snyder, D. K., Cigrang, J., Talcott, G. W., Tatum, J., Baker, M., et al. (2013) Combat disclosure in intimate relationships: mediating the impact of partner support on posttraumatic stress. Journal of family psychology: JFP: Journal of the Division of Family Psychology of the American Psychological Association (Division 43), 27(4), 560-568, doi:https://doi. org/10.1037/a0033412.

Bankole, A., Singh, S., \& Haas, T. (1998). Reasons why women have induced abortions: Evidence from 27 countries. International Family Planning Perspectives, 24(3), 117. https://doi.org/10.2307/3038208.

Berg, C. A., \& Upchurch, R. (2007). A developmental-contextual model of couples coping with chronic illness across the adult life span. Psychological Bulletin, 133(6), 920-954. https://doi. org/10.1037/0033-2909.133.6.920.

Bergant, A. M., Reinstadler, K., Moncayo, H. E., Solder, E., Heim, K., Ulmer, H., et al. (1997). Spontaneous abortion and psychosomatics. A prospective study on the impact of psychological factors as a cause for recurrent spontaneous abortion. Human Reproduction, 12(5), 1106-1110. https://doi.org/10.1093/ humrep/12.5.1106.

Biggs, M. A., Gould, H., Barar, R. E., \& Foster, D. G. (2018). Five-year suicidal ideation trajectories among women receiving or being denied an abortion. The American Journal of Psychiatry, 175(9), 845-852. https://doi.org/10.1176/appi.ajp.2018.18010091.

Biggs, M. A., Gould, H., \& Foster, D. G. (2013). Understanding why women seek abortions in the US. BMC Women's Health, 13, 29. https://doi.org/10.1186/1472-6874-13-29.

Biggs, M. A., Upadhyay, U. D., McCulloch, C. E., \& Foster, D. G. (2017). Women's mental health and wellbeing 5 years after receiving or being denied an abortion: A prospective longitudinal cohort study. JAMA Psychiatry, 74(2), 169-178. https://doi.org/10.1001/jamapsychiatry.2016.3478.

Biggs, M. A., Upadhyay, U. D., Steinberg, J. R., \& Foster, D. G. (2014). Does abortion reduce self-esteem and life satisfaction? Quality of Life Research, 23(9), 2505-2513. https://doi.org/10.1007/s1113 6-014-0687-7.

Blanchflower, D. G., \& Oswald, A. J. (2008). Is well-being U-shaped over the life cycle? Social Science \& Medicine, 66(8), 1733-1749. https://doi.org/10.1016/j.socscimed.2008.01.030.

Bodenmann, G. (1997). Dyadic coping-a systematic-transactional view of stress and coping among couples: Theory and empirical findings. European Review of Applied Psychology, 47, 137-140.

Bowles, S. V., James, L. C., Solursh, D. S., Yancey, M. K., Epperly, T. D., Folen, R. A., et al. (2000). Acute and post-traumatic stress disorder after spontaneous abortion. American Family Physician, 61(6), 1689-1696.

Broen, A. N., Moum, T., Bødtker, A. S., \& Ekeberg, O. (2005). The course of mental health after miscarriage and induced abortion: A longitudinal, five-year follow-up study. BMC Medicine, 3, 18. https:// doi.org/10.1186/1741-7015-3-18. 
Brüderl, J., Drobnič, S., Hank, K., Neyer, F. J., Walper, S., Alt, P., et al. (2020). The German Family Panel (pairfam).

Brüderl, J., \& Ludwig, V. (2015). Fixed-effects panel regression. In H. Best \& C. Wolf (Eds.), The sage handbook of regression analysis and causal inference (pp. 327-257). Los Angeles, Calif., London, New Delhi, Singapore, Washington DC: Sage reference.

Charles, V. E., Polis, C. B., Sridhara, S. K., \& Blum, R. W. (2008). Abortion and long-term mental health outcomes: A systematic review of the evidence. Contraception, 78(6), 436-450. https://doi. org/10.1016/j.contraception.2008.07.005.

Cheung, F., \& Lucas, R. E. (2014). Assessing the validity of single-item life satisfaction measures: Results from three large samples. Quality of Life Research, 23(10), 2809-2818. https://doi.org/10.1007/s1113 6-014-0726-4.

Cohen, S. A. (2006). Abortion and mental health: Myths and realities. Guttmacher Policy Review, 9(3), $8-16$.

Coleman, P. K. (2006). Resolution of unwanted pregnancy during adolescence through abortion versus childbirth: Individual and family predictors and psychological consequences. Journal of Youth and Adolescence, 35(6), 903-911. https://doi.org/10.1007/s10964-006-9094-x.

Coleman, P. K., Reardon, D. C., \& Strahan †, T., \& Cougle, J. R. . (2005). The psychology of abortion: A review and suggestions for future research. Psychology \& Health, 20(2), 237-271. https://doi. org/10.1080/0887044042000272921.

Cougle, J. R., Reardon, D. C., \& Coleman, P. K. (2003). Depression associated with abortion and childbirth: A Long-term analysis of the NLSY cohort. Medical Science Monitor : International Medical Journal of Experimental and Clinical Research, 9(4), 157-164.

Cougle, J. R., Reardon, D. C., \& Coleman, P. K. (2005). Generalized anxiety following unintended pregnancies resolved through childbirth and abortion: A cohort study of the 1995 national survey of family growth. Journal of Anxiety Disorders, 19(1), 137-142. https://doi.org/10.1016/j.janxd is.2003.12.003.

Curtis, C. (2007). Meeting health care needs of women experiencing complications of miscarriage and unsafe abortion: USAID's postabortion care program. Journal of Midwifery \& Women's Health, 52(4), 368-375. https://doi.org/10.1016/j.jmwh.2007.03.005.

Diener, E., \& Chan, M. Y. (2011). Happy people live longer: Subjective well-being contributes to health and longevity. Applied Psychology: Health and Well-Being, 3(1), 1-43. https://doi.org/10.111 1/j.1758-0854.2010.01045.x.

Diener, E., Inglehart, R., \& Tay, L. (2013). Theory and validity of life satisfaction scales. Social Indicators Research, 112(3), 497-527. https://doi.org/10.1007/s11205-012-0076-y.

Engelhard, I. M. (2004). Miscarriage as a traumatic event. Clinical Obstetrics and Gynecology, 47(3), 547-551. https://doi.org/10.1097/01.grf.0000129920.38874.0d.

Federal Statistical Office of Germany (2020). Gesundheit: Schwangerschaftsabbrüche bis 2019 [Health: Induced Abortions until 2019] (Fachserie 12 3).

Fergusson, D. M., Horwood, L. J., \& Ridder, E. M. (2006). Abortion in young women and subsequent mental health. Journal of Child Psychology and Psychiatry, and Allied Disciplines, 47(1), 16-24. https://doi.org/10.1111/j.1469-7610.2005.01538.x.

Finer, L. B., Frohwirth, L. F., Dauphinee, L. A., Singh, S., \& Moore, A. M. (2005). Reasons U.S. women have abortions: quantitative and qualitative perspectives. Perspectives on Sexual and Reproductive Health, 37(3), 110-118. https://doi.org/10.1363/psrh.37.110.05.

Finer, L. B., \& Henshaw, S. K. (2003). Abortion incidence and services in the United States in 2000. Perspectives on Sexual and Reproductive Health, 35(01), 6-15. https://doi.org/10.1363/3500603.

García-Enguídanos A., Calle M., Valero J., Luna S., Domínguez-Rojas V. (2002). Risk factors in miscarriage: A review. European Journal of Obstetrics \& Gynecology and Reproductive Biology, 102( 2), 111-119, doi:https://doi.org/10.1016/S0301-2115(01)00613-3.

Gold, K. J., Boggs, M. E., Mugisha, E., \& Palladino, C. L. (2012). Internet message boards for pregnancy loss: who's on-line and why? Women's Health Issues : Official Publication of the Jacobs Institute of Women's Health, 22(1), e67-72. https://doi.org/10.1016/j.whi.2011.07.006.

Gold KJ, Leon I, Boggs ME, Sen A. (2016). Depression and posttraumatic stress symptoms after perinatal loss in a population-based sample. Journal of women's health (2002), 25(3), 263-269, doi:https ://doi.org/10.1089/jwh.2015.5284.

Gold, K. J., Sen, A., \& Hayward, R. A. (2010). Marriage and cohabitation outcomes after pregnancy loss. Pediatrics, 125(5), e1202-e1207. https://doi.org/10.1542/peds.2009-3081.

Gravensteen, I. K., Jacobsen, E.-M., Sandset, P. M., Helgadottir, L. B., Rådestad, I., Sandvik, L., et al. (2018). Anxiety, depression and relationship satisfaction in the pregnancy following stillbirth and 
after the birth of a live-born baby: A prospective study. BMC Pregnancy and Childbirth, 18(1), 41. https://doi.org/10.1186/s12884-018-1666-8.

Grussu, P., Quatraro, R. M., \& Nasta, M. T. (2005). Profile of Mood States and parental attitudes in motherhood: comparing women with planned and unplanned pregnancies. Birth (Berkeley, Calif.), 32(2), 107-114, doi:https://doi.org/10.1111/j.0730-7659.2005.00353.x.

Hanschmidt, F., Linde, K., Hilbert, A., Riedel-Heller, S. G., \& Kersting, A. (2016). Abortion stigma: A systematic review. Perspectives on Sexual and Reproductive Health, 48(4), 169-177. https://doi. org/10.1363/48e 8516 .

Hansen, T. (2012). Parenthood and happiness: A review of folk theories versus empirical evidence. Social Indicators Research, 108(1), 29-64. https://doi.org/10.1007/s11205-011-9865-y.

Hatzenbuehler, M. L., Phelan, J. C., \& Link, B. G. (2013). Stigma as a fundamental cause of population health inequalities. American Journal of Public Health, 103(5), 813-821. https://doi.org/10.2105/ AJPH.2012.301069.

Haukoos, J. S., \& Lewis, R. J. (2015). The Propensity Score. JAMA, 314(15), 1637-1638. https://doi. org/10.1001/jama.2015.13480.

Headey, B. (2007). The set-point theory of well-being: negative results and consequent revisions. Social Indicators Research, 85(3), 389-403. https://doi.org/10.1007/s11205-007-9134-2.

Headey, B., Veenhoven, R., \& Wearing, A. (1991). Top-down versus bottom-up theories of subjective wellbeing. Social Indicators Research, 24(1), 81-100. https://doi.org/10.1007/BF00292652.

Headey, B., \& Wearing, A. (1989). Personality, life events, and subjective well-being: Toward a dynamic equilibrium model. Journal of Personality and Social Psychology, 57(4), 731-739. https://doi. org/10.1037/0022-3514.57.4.731.

Helgeson, V. S., Jakubiak, B., van Vleet, M., \& Zajdel, M. (2018). Communal coping and adjustment to chronic illness: Theory update and evidence. Personality and social psychology review : an official journal of the Society for Personality and Social Psychology, Inc, 22(2), 170-195, doi:https://doi. org/10.1177/1088868317735767.

Horvath, S., \& Schreiber, C. A. (2017). Unintended pregnancy, induced abortion, and mental health. Current Psychiatry Reports, 19(11), 77. https://doi.org/10.1007/s11920-017-0832-4.

Huinink, J., Brüderl, J., Nauck, B., Walper, S., Castiglioni, L., \& Feldhaus, M. (2011). Panel analysis of intimate relationships and family Dynamics (pairfam): Conceptual framework and design. Zeitschrift für Familienforschung - Journal of Family Research, 23(1), 77-101.

Hurt, K. J., Guile, M. W., Bienstock, J. L., Fox, H. E., \& Walach, E. E. (2011). The Johns Hopkins manual of gynecology and obstetrics (4th edn, A Lippincott manual). Philadelphia: Wolters Kluwer Health/ Lippincott Williams \& Wilkins.

Huss, B., \& Pollmann-Schult, M. (2020). Relationship satisfaction across the transition to parenthood: The impact of conflict behavior. Journal of Family Issues, 41(3), 383-411. https://doi.org/10.1177/01925 $13 \mathrm{X} 19876084$.

Jones, R. K., \& Kost, K. (2007). Underreporting of induced and spontaneous abortion in the United States: An analysis of the 2002 national survey of family growth. Studies in Family Planning, 38(3), 187197. https://doi.org/10.1111/j.1728-4465.2007.00130.x.

Kainz, K., Greifer, N., Givens, A., Swietek, K., Lombardi, B. M., Zietz, S., et al. (2017). Improving causal inference: Recommendations for covariate selection and balance in propensity score methods. Journal of the Society for Social Work and Research, 8(2), 279-303. https://doi.org/10.1086/691464.

Kelley, M. C., \& Trinidad, S. B. (2012). Silent loss and the clinical encounter: Parents' and physicians' experiences of stillbirth-a qualitative analysis. BMC Pregnancy and Childbirth, 12, 137. https://doi. org/10.1186/1471-2393-12-137.

Kersting, A., \& Wagner, B. (2012). Complicated grief after perinatal loss. Dialogues in Clinical Neuroscience, 14(2), 187-194.

Klier, C. M., Geller, P. A., \& Ritsher, J. B. (2002). Affective disorders in the aftermath of miscarriage: A comprehensive review. Archives of Women's Mental Health, 5(4), 129-149. https://doi.org/10.1007/ s00737-002-0146-2.

Kong, G. W. S., Lok, I. H., Yiu, A. K. W., Hui, A. S. Y., Lai, B. P. Y., \& Chung, T. K. H. (2013). Clinical and psychological impact after surgical, medical or expectant management of first-trimester miscarriage - a randomised controlled trial. The Australian \& New Zealand Journal of Obstetrics \& Gynaecology, 53(2), 170-177. https://doi.org/10.1111/ajo.12064.

Korenman, S., Kaestner, R., \& Joyce, T. J. (2001). Unintended pregnancy and the consequences of nonmarital childbearing. In: L. L. Wu \& B. Wolfe (Eds.), Out of Wedlock (pp. 259-286, Causes and Consequences of Nonmarital Fertility): Russell Sage Foundation.

Lucas, R. E. (2007). Adaptation and the set-point model of subjective well-being. Current Directions in Psychological Science, 16(2), 75-79. https://doi.org/10.1111/j.1467-8721.2007.00479.x. 
Lucas, R. E., \& Donnellan, M. B. (2012). Estimating the reliability of single-item life satisfaction measures: Results from four national panel studies. Social Indicators Research, 105(3), 323-331. https://doi. org/10.1007/s11205-011-9783-z.

Luhmann, M., Hofmann, W., Eid, M., \& Lucas, R. E. (2012). Subjective well-being and adaptation to life events: A meta-analysis. Journal of Personality and Social Psychology, 102(3), 592-615. https://doi. org/10.1037/a0025948.

Luhmann, M., Lucas, R. E., Eid, M., \& Diener, E. (2013). The Prospective effect of life satisfaction on life events. Social Psychological and Personality Science, 4(1), 39-45. https://doi.org/10.1177/19485 50612440105.

Major, B., Appelbaum, M., Beckman, L., Dutton, M. A., Russo, N. F., \& West, C. (2008). Report of the APA task force on mental health and abortion. Washington, D.C.: American Psychological Association.

Major, B., Appelbaum, M., Beckman, L., Dutton, M. A., Russo, N. F., \& West, C. (2009). Abortion and mental health: Evaluating the evidence. The American Psychologist, 64(9), 863-890. https://doi. org/10.1037/a0017497.

Major, B., Cozzarelli, C., Cooper, M. L., Zubek, J., Richards, C., Wilhite, M., et al. (2000). Psychological responses of women after first-trimester abortion. Archives of general psychiatry, 57(8), 777-784. https://doi.org/10.1001/archpsyc.57.8.777.

Major, B., \& O'Brien, L. T. (2005). The social psychology of stigma. Annual Review of Psychology, 56, 393421. https://doi.org/10.1146/annurev.psych.56.091103.070137.

Major, B., Zubek, J. M., Cooper, M. L., Cozzarelli, C., \& Richards, C. (1997). Mixed messages: Implications of social conflict and social support within close relationships for adjustment to a stressful life event. Journal of Personality and Social Psychology, 72(6), 1349-1363. https://doi.org/10.1037/0022-3514.72.6.1349.

Mekosh-Rosenbaum, V., \& Lasker, J. N. (1995). Effects of pregnancy outcomes on marital satisfaction: A longitudinal study of birth and loss. Infant Mental Health Journal, 16(2), 127-143. https://doi. org/10.1002/1097-0355(199522)16:2\%3c127:AID-IMHJ2280160207\%3e3.0.CO;2-6.

Miall, C. E. (1986). The stigma of involuntary childlessness sexuality: Private Troubles and deviant careers. Social Problems, 33.

Miller, W. B., Pasta, D. J., \& Dean, C. L. (1998). Testing a model of the psychological consequences of abortion. In: L. J. Beckman \& S. M. Harvey (Eds.), The new civil war: The psychology, culture, and politics of abortion (pp. 235-267, Psychology of women book series). Washington, D.C.: American Psychological Association.

Morgan, S. L., \& Winship, C. (2015). Counterfactuals and causal inference: Methods and principles for social research (2nd edn, Analytical methods for social research). New York, NY: Cambridge University Press.

National Collaborating Centre for Mental Health. (2011). Induced abortion and mental health: A systematic review of the mental health outcomes of induced abortion, including their prevalence and associated factors. London: Academy of Medical Royal Colleges.

Nelson, S. K., Kushlev, K., \& Lyubomirsky, S. (2014). The pains and pleasures of parenting: When, why, and how is parenthood associated with more or less well-being? Psychological Bulletin, 140(3), 846-895. https://doi.org/10.1037/a0035444.

NICHD (2019). Pregnancy loss / stillbirth. https://www.nichd.nih.gov/health/topics.

Oliver, A., Overton, C. (2014). Diagnosis and management of miscarriage. The Practitioner, 258(1771), 25-8, 3.

Pereira, J., Pires, R., \& Canavarro, M. C. (2017). Psychosocial adjustment after induced abortion and its explanatory factors among adolescent and adult women. Journal of Reproductive and Infant Psychology, 35(2), 119-136. https://doi.org/10.1080/02646838.2016.1276281.

Ralph, L. J., Foster, D. G., Rocca, C. H. (2020). Comparing prospective and retrospective reports of pregnancy intention in a longitudinal cohort of U.S. women. Perspectives on sexual and reproductive health, 52(1), 39-48, doi:https://doi.org/10.1363/psrh.12134.

Reardon, D. C., \& Cougle, J. R. (2002). Depression and unintended pregnancy in the national longitudinal survey of youth: A cohort study. BMJ, 324(7330), 151-152. https://doi.org/10.1136/bmj.324.7330.151.

Renner, R.-M., de Guzman, A., \& Brahmi, D. (2014). Abortion care for adolescent and young women. International Journal of Gynaecology and Obstetrics: The Official Organ of the International Federation of Gynaecology and Obstetrics, 126(1), 1-7. https://doi.org/10.1016/j.ijgo.2013.07.034.

Rich, S., Taket, A., Graham, M., \& Shelley, J. (2011). 'Unnatural', 'unwomanly', 'uncreditable' and 'undervalued': The significance of being a childless woman in Australian society. Gender Issues, 28(4), 226-247. https://doi.org/10.1007/s12147-011-9108-1.

Rissanen, T., Viinamäki, H., Honkalampi, K., Lehto, S. M., Hintikka, J., Saharinen, T., et al. (2011). Long term life dissatisfaction and subsequent major depressive disorder and poor mental health. BMC psychiatry, 11, 140. https://doi.org/10.1186/1471-244X-11-140. 
Robinson, G. E., Stotland, N. L., Russo, N. F., Lang, J. A., \& Occhiogrosso, M. (2009). Is there an "abortion trauma syndrome"? Critiquing the evidence. Harvard Review of Psychiatry, 17(4), 268-290. https://doi. org/10.1080/10673220903149119.

Rocca, C. H., Kimport, K., Gould, H., \& Foster, D. G. (2013). Women's emotions one week after receiving or being denied an abortion in the United States. Perspectives on Sexual and Reproductive Health, 45(3), 122-131. https://doi.org/10.1363/4512213.

Rocca, C. H., Samari, G., Foster, D. G., Gould, H., Kimport, K. (2020). Emotions and decision rightness over five years following an abortion: An examination of decision difficulty and abortion stigma. Social science \& medicine (1982), 248, 112704, doi: https://doi.org/10.1016/j.socscimed.2019.112704.

Rocca, C. H., Wilson, M. R., Jeon, M., \& Foster, D. G. (2019). Stability of retrospective pregnancy intention reporting among women with unwanted pregnancies in the United States. Maternal and Child Health Journal, 23(11), 1547-1555. https://doi.org/10.1007/s10995-019-02782-9.

Russo, N. F., \& Dabul, A. J. (1997). The relationship of abortion to well-being: Do race and religion make a difference? Professional Psychology: Research and Practice, 28(1), 23-31. https://doi. org/10.1037/0735-7028.28.1.23.

Savage, L. J. (2012). The foundations of statistics. New York: Dover Publications.

Schwerdtfeger, K. L., \& Shreffler, K. M. (2009). Trauma of pregnancy loss and infertility for mothers and involuntarily childless women in the contemporary United States. Journal of Loss \& Trauma, 14(3), 211-227. https://doi.org/10.1080/15325020802537468.

Sedgh, G., Singh, S., Shah, I. H., Åhman, E., Henshaw, S. K., \& Bankole, A. (2012). Induced abortion: Incidence and trends worldwide from 1995 to 2008. The Lancet, 379(9816), 625-632. https://doi. org/10.1016/S0140-6736(11)61786-8.

Serrano, F., \& Lima, M. L. (2006). Recurrent miscarriage: Psychological and relational consequences for couples. Psychology and Psychotherapy: Theory, Research and Practice, 79(4), 585-594. https://doi. org/10.1348/147608306X96992.

Shreffler, K. M., Hill, P. W., \& Cacciatore, J. (2012). Exploring the increased odds of divorce following miscarriage or stillbirth. Journal of Divorce \& Remarriage, 53(2), 91-107. https://doi.org/10.1080/10502 556.2012 .651963$.

Speckhard, A. C. (1997). Traumatic death in pregnancy: The significance of meaning and attachment. In C. R. Figley, B. E. Bride, \& N. Mazza (Eds.), Death and trauma: The traumatology of grieving (pp. 67-100, The series in trauma and loss). Washington, DC: Taylor \& Francis.

Speckhard, A. C., \& Rue, V. M. (1992). Postabortion syndrome: An emerging public health concern. Journal of Social Issues, 48(3), 95-119. https://doi.org/10.1111/j.1540-4560.1992.tb00899.x.

Steinberg, J. R., Finer, L. B. (2011). Examining the association of abortion history and current mental health: A reanalysis of the National Comorbidity Survey using a common-risk-factors model. Social science \& medicine (1982), 72(1), 72-82, doi: https://doi.org/10.1016/j.socscimed.2010.10.006.

Steinberg, J. R., McCulloch, C. E., \& Adler, N. E. (2014). Abortion and mental health: Findings from the national comorbidity survey-replication. Obstetrics and Gynecology, 123(2 Pt 1), 263-270. https://doi. org/10.1097/AOG.0000000000000092.

Steinberg, J. R., \& Rubin, L. R. (2014). Psychological aspects of contraception, unintended pregnancy, and abortion. Policy Insights from the Behavioral and Brain Sciences, 1(1), 239-247. https://doi. org/10.1177/2372732214549328.

Steinberg, J. R., Russo, N. F. (2008). Abortion and anxiety: what's the relationship? Social science \& medicine (1982), 67(2), 238-252, doi: https://doi.org/10.1016/j.socscimed.2008.03.033.

Stotland, N. L. (2003). Abortion and psychiatric practice. Journal of Psychiatric Practice, 9(2), 139-149.

Stuart, E. A. (2010). Matching methods for causal inference: A review and a look forward. Statistical Science, 25(1), 1-21. https://doi.org/10.1214/09-STS313.

Suh, E., Diener, E., \& Fujita, F. (1996). Events and subjective well-being: Only recent events matter. Journal of Personality and Social Psychology, 70(5), 1091-1102. https://doi.org/10.1037/0022-3514.70.5.1091.

Sundstrom, B. (2014). Breaking women's health taboos. Social Marketing Quarterly, 20(2), 87-102. https://doi. org/10.1177/1524500414525774.

Swanson, K. M., Chen, H.-T., Graham, J. C., Wojnar, D. M., \& Petras, A. (2009). Resolution of depression and grief during the first year after miscarriage: A randomized controlled clinical trial of couplesfocused interventions. Journal of women's health (2002), 18(8), 1245-1257, doi: https://doi.org/10.1089/ jwh.2008.1202.

Taft, A. J., \& Watson, L. F. (2008). Depression and termination of pregnancy (induced abortion) in a national cohort of young Australian women: the confounding effect of women's experience of violence. $B M C$ Public Health, 8(75), 1-8. https://doi.org/10.1186/1471-2458-8-75. 
Touburg, G., \& Veenhoven, R. (2015). Mental health care and average happiness: Strong effect in developed nations. Administration and Policy in Mental Health, 42(4), 394-404. https://doi.org/10.1007/s1048 8-014-0579-8.

van Ditzhuijzen, J., ten Have, M., de Graaf, R., van Nijnatten, C. H. C. J., \& Vollebergh, W. A. M. (2013). Psychiatric history of women who have had an abortion. Journal of Psychiatric Research, 47(11), 17371743. https://doi.org/10.1016/j.jpsychires.2013.07.024.

Wanous, J. P., Reichers, A. E., \& Hudy, M. J. (1997). Overall job satisfaction: How good are single-item measures? Journal of Applied Psychology, 82(2), 247.

Westerhof, G. J., \& Keyes, C. L. M. (2010). Mental illness and mental health: The two continua model across the lifespan. Journal of Adult Development, 17(2), 110-119. https://doi.org/10.1007/s10804-009-9082-y.

Publisher's Note Springer Nature remains neutral with regard to jurisdictional claims in published maps and institutional affiliations. 